\title{
Course of bereavement over 8-10 years in first degree relatives and spouses of people who committed suicide: longitudinal community based cohort study
} (ㄷ) (1) \& OPEN ACCESS

\author{
Marieke de Groot senior researcher ${ }^{123}$, Boudewijn J Kollen senior researcher department of general \\ practice medicine ${ }^{1}$
}

'University of Groningen/University Medical Center Groningen, PO Box 30.001, 9700 RB Groningen, Netherlands; ${ }^{2}$ VU University, Van der Boechorststraat 1, 1081 BT Amsterdam, Netherlands; ${ }^{3} \mathrm{EMGO}+$ Institute for Heath and Care Research, Amsterdam, Netherlands

\begin{abstract}
Objective To identify factors predicting the long term course of complicated grief, depression, and suicide ideation in a community based sample of relatives bereaved through suicide.

Design Longitudinal cohort study. Included in the multilevel regression models were sociodemographic and personality features, mental health history, records of received help, long term complicated grief, depression, and suicide ideation.

Setting Community based sample located in the northern part of the Netherlands.

Participants 153 first degree relatives and spouses of 74 people who had committed suicide.

Main outcome measures Complicated grief, depression, and suicide ideation assessed at 2.5 months, 13 months and 96-120 months (8-10 years) by means of self report questionnaires.

Results Complicated grief, depression, and suicide ideation were mutually associated in relatives and spouses of people who had committed suicide. A history of attempted suicide was associated with long term suicide ideation (odds ratio 5.5, 95\% confidence interval 1.8 to $16.7 ; P=0.003$ ). Depression was more likely to be predicted by female sex and low mastery, whereas complicated grief was more likely to be predicted by the trauma of losing a child. The risk of both complicated grief and depression decreased over time; for complicated grief the change corresponded with a Cohen's d effect size of 0.36 at 13 months and 0.89 at $96-120$ months; for depression these figures were 0.28 at 13 months and 0.94 at $96-120$ months. The long term course of bereavement was not affected by family based cognitive behavioural therapy, support from a general practitioner, and/or mental healthcare. Mutual support was associated with an increased risk of complicated grief: B regression coefficient $=6.4$ (95\% confidence interval 1.8 to 11.0 ; $\mathrm{P}=0.006$ ). Throughout this long term study, selection bias might have affected some outcomes.
\end{abstract}

Conclusion In relatives bereaved by suicide, suicide ideation is associated with an increased risk of long term complicated grief and depression. The risk of complicated grief and depression decreases over time. Although mutual support is associated with an increased risk of complicated grief, we could not draw conclusions about a causal relation.

\section{Introduction}

Suicide is an important public health issue, with a global mortality rate estimated at 16 per $100000 .{ }^{1}$ It is estimated that one in 64 people in the United States knows someone who committed suicide. ${ }^{2}$ A family history of suicidal behaviour is associated with an increased risk of suicide in both genetically and non-genetically related relatives such as spouses, in-laws, and friends of the deceased. ${ }^{3}$ Bereavement increases the risk of mortality, ${ }^{4}$ and the risk is even higher after bereavement by suicide. ${ }^{5}$ Symptoms of complicated grief might contribute to the increased risk of suicide in relatives bereaved by suicide. Complicated grief is a proposed clinical entity distinct from depression, anxiety, and post-traumatic stress disorder related to bereavement. ${ }^{6}$ It is characterised by preoccupation with the deceased, avoidance, disbelief, numbness, detachment, and excessive irritability and anger and is associated with long term somatic and psychiatric (co)morbidity ${ }^{7}$ and suicide ideation, even after adjustment for depression. ${ }^{8}{ }^{9}$ Prevention and/or treatment of complicated grief can decrease the risk of suicidal behaviour and contribute to suicide prevention; however, this has not yet been clinically investigated. Until now, mechanisms underlying the association between complicated grief and suicide ideation remain unclear.

Grief counselling can be effective in decreasing the risk of problematic grief in individuals at increased risk of adverse bereavement outcome. ${ }^{4}$ Despite the high risk status of relatives 
bereaved by suicide, however, there is no clear evidence for the effectiveness of such programmes. ${ }^{10}$ Relatives usually seek help from their general practitioner, who would usually refer these patients to mental healthcare or to "mutual support." ${ }^{11}$ Mutual support is a common type of intervention for people experiencing life events with serious consequences. In the context of our study, mutual support refers to contact with a person outside the family who has also lost a loved one through suicide and who was not a friend or acquaintance before the index suicide. There is no sound evidence for the efficacy of mutual support for adults in the aftermath of suicide. ${ }^{2} \mathrm{~A}$ randomised controlled trial in a community based sample of first degree relatives and spouses recently bereaved by suicide (the Survivors at Risk study ${ }^{12}$ ) examined the effect of four sessions of family based cognitive behavioural therapy offered at three to six months after the loss versus usual care on the risk of complicated grief. Although the therapy had no overall beneficial effect on the risk of complicated grief, depression, or suicide ideation, it was more helpful than usual care in reducing perceptions of guilt. Relatives who experienced suicide ideation at three months after loss (that is, about $20 \%$ of those recently bereaved by suicide ${ }^{21314}$ ) were more likely to have a history of clinical depression, anxiety, and attempted suicide. These relatives also showed more symptoms of complicated grief and depression up to 13 months after loss compared with relatives without suicide ideation. Post hoc analyses showed that family based cognitive behavioural therapy decreased the risk of complicated grief in relatives who suffered from suicide ideation, and that those with suicide ideation immediately after the loss might have a greater potential to benefit from such therapy. ${ }^{14}$

Most studies on the course of bereavement after a suicide focus on the short or median term course. We investigated the long term course of bereavement in first degree relatives and spouses of people who had committed suicide. We explored associations between sociodemographic characteristics of the deceased, sociodemographic and personality features of the bereaved, and symptoms of complicated grief, depression, and suicide ideation up to eight to 10 years after the index suicide. We hypothesised that a history of attempted suicide is associated with a long term increased risk of complicated grief, depression, and suicide ideation after the index suicide. In addition, we explored associations between symptom levels and various help resources, including family based cognitive behavioural therapy.

\section{Methods}

In a cohort study, data were derived from a community based sample of 153 first degree relatives (aged >15) and spouses of 74 individuals who had committed suicide between September 1999 and January 2002 in the northern part of the Netherlands. A total of 122 members of 70 families previously participated in a cluster randomised controlled trials on the effectiveness of family based cognitive behavioural therapy to reduce the risk of complicated grief. ${ }^{12}$ Of the initial 153 participants, 31 were excluded from analyses in the randomised controlled trial because they were included after randomisation; however, these latter participants were included in the present study.

Families were considered as clusters, and these clusters were randomly allocated to either family based cognitive behavioural therapy or usual care. Of the 74 families, 41 received four sessions of therapy three to six months after the suicide $(n=92)$ and 33 families $(n=61)$ received care as usual. As 24/31 participants $(77 \%)$ in the non-randomised group belonged to a cluster that had been allocated to the intervention condition, we assume that non-randomised participants were more likely to participate in the study if the cluster they belonged to had been allocated to receive family based cognitive behavioural therapy. Study participants were recruited by the general practitioner of the person who died. The general practitioners were informed about the study by the local coroner in all cases of suicide. Exclusion criteria were relatives' lack of fluency in Dutch and/or imprisonment. The eligibility of the relative to be approached was left to the discretion of the general practitioners. All participants $(n=153)$ completed self report baseline assessments at 2.5 months after the suicide (T0). Self report follow-up assessments (T1) were made at 13 months after the suicide. At T1, two trained nurses also carried out semi-structured interviews to assess the participant's lifetime mental health before the index suicide. These two nurses had not previously been in contact with any of the participants. Full details are published elsewhere. ${ }^{15}$

After completing T1, 139 participants provided written consent to participate in a future follow-up study, conducted between January 2009 and February 2010. A second follow-up assessment (T2) took place among those who consented to participate after T1 $(\mathrm{n}=119 / 139 ; 86 \%)$. Participants were invited by letter and received (at most) two reminders in case of non-response. If they had moved away or if the letter was returned undeliverable, the general practitioners were requested to provide, if applicable, a (new) address or the name of the new general practitioner. Participants were approached only if the (former or current) general practitioner agreed with study participation. Participants consented by completing and returning the enrolment form. If the new address or the name of the new general practitioner remained unknown, or if the general practitioner did not agree with participation, cases were excluded $(n=20)$.

\section{Measurement}

Sociodemographic features-At T0, we assessed sociodemographic and personality features of the participants. The various dichotomous kinship relationships were transformed into one multi-categorical (nominal) variable, with the "a spouse" set as reference category.

Personality features-Neuroticism, representing individuals' vulnerability for mental disorder, ${ }^{16}$ was measured with the revised Eysenck personality questionnaire (EPQ-RSS), ${ }^{17}$ with higher scores (range 0-12) indicating higher neuroticism. Mastery, representing the general degree to which a person experiences control over what goes on in his or her life, was measured with the scale of Pearlin and Schooler, ${ }^{18}$ with higher scores (range 7-35) indicating a lower sense of control. Self esteem was assessed with the Rosenberg self esteem scale (RSES), ${ }^{19}$ with higher scores (range 10-40) indicating higher self esteem. We measured mastery and self esteem because a loss due to suicide might be less threatening to individuals with high self esteem and high internal control beliefs. ${ }^{20}$

Mental health - Complicated grief was measured with the Dutch version of the inventory of traumatic grief (ITG) (range 29-145); higher scores indicating a higher risk of complicated grief. ${ }^{21}$ Depressive symptoms during the past week were assessed with the Center for Epidemiologic Studies depression scale (CES-D), ${ }^{22}$ with higher scores (range 0-60) indicating a higher risk of clinical depression. Suicide ideation in the previous month was assessed with the Paykel suicide items (PSI) (range 4-20). ${ }^{23}$ Individuals with a score $>8$ were considered suicidal ${ }^{12}$. History of mental health-Lifetime attempted suicide was assessed at T0 with the question: "before the suicide of your 
relative/spouse, have you ever attempted suicide?" (1=yes, $0=$ no). Depression and anxiety before the loss were assessed with questions of the SCAN 2.1 (schedules for clinical assessment in neuropsychiatry). ${ }^{24}$ Symptoms were scored on a 4 point ordinal scale $(0=$ no complaints, $3=$ severe complaints). In case of a possible clinical episode (score $>0$ ), former episodes were explored regarding the degree of discomfort $(1=$ no discomfort to $3=$ =severe discomfort), use of primary healthcare, use of mental healthcare services, drug use, the need to be absent from work or school, and/or persisting complaints (scored in a $1=$ yes, $0=$ no format). A clinical episode was established if, during at least one episode, the participants felt moderate to severe inconvenience from the complaints (score $>0$ ) and quit school or work, and/or made use of mental healthcare service, and/or used psychotropic drugs during an episode, and/or if complaints persisted. Depression and anxiety disorder were scored separately ( $0=$ absent, $1=$ present $)$.

Help seeking-Participants indicated whether or not they had received help from their general practitioner $(1=$ yes, $0=$ no), and/or inpatient or outpatient mental healthcare $(1=$ yes, $0=$ no), and/or had sought contact with other people bereaved by suicide who initially were not relatives or friends $(1=$ yes, $0=$ no); these latter contacts were considered to be "mutual support." At T0 participants indicated which help resources had been used from the time of the suicide up until T0, at T1 they indicated the help resources used between $\mathrm{T} 0$ and $\mathrm{T} 1$, and at $\mathrm{T} 2$ the help resources used between $\mathrm{T} 1$ and $\mathrm{T} 2$. All dependent variables were observed at $\mathrm{T} 0, \mathrm{~T} 1$, and $\mathrm{T} 2$ except for personality features at $\mathrm{T} 0$ and mental health history at $\mathrm{T} 1$.

\section{Data analysis}

Sample characteristics were analysed with descriptive statistics with SPSS (version 19). Multilevel analyses were conducted with MLwiN 2.20 software. Outcome and predictor variables (except demographic and personality features and history of mental health) were repeatedly measured over time. As a consequence, repeated observations (level 1) were nested within the participant, while the participants (level 2) were nested within families (level 3). Multilevel models are hierarchical systems that estimate regression coefficients and variance components for each level. Random intercepts were included in the longitudinal prediction models. Significance of the $\beta$ coefficient was based on the Wald test. We used iterative generalised least squares algorithm to estimate the regression coefficients and assessed the assumptions of normality and homogeneity of the variance by inspecting normal probability plots and plots of standardised residual versus predicted values.

Firstly, we conducted a missing value analysis using SPSS software to identify patterns in missing values of variables. This analysis showed that the missing values in our data occurred primarily and progressively in variables that were measured longitudinally - that is, response and potential predictors variables. Subsequently, we analysed whether baseline characteristics differed between participants with missing data and those without missing data for the response variables (long term complicated grief and depression) at the final measurement. Based on these analyses we concluded that missing values were probably due to the scores of the response variables-that is, missing not at random (MNAR). Based on this analysis, we decided not to impute missing values and to conduct an available case analysis. Under the assumption of MNAR, we developed linear multilevel regression prediction models with only significant variables that best explained the variance of the complicated grief and depression response variables in our population.
Initially, we examined bivariate associations between the outcome variables and individual factors. The following factors were selected to predict complicated grief, depression, and suicide ideation: sociodemographic features (sex of the respondent, relationship to the deceased); personality features of the bereaved (neuroticism, mastery, self esteem); history of mental health (previous episodes of clinical depression and anxiety, a history of attempted suicide) and help resources (family based cognitive behavioural therapy, primary healthcare, mental healthcare, and mutual support); long term suicide ideation, depression, and complicated grief; and time of measurement. The independent variables that showed a significant association with outcome $(\mathrm{P} \leq 0.05)$ were subsequently fitted in a multivariate longitudinal prediction model, based on a best subset backward selection strategy. Multivariate multilevel prediction regression models for long term complicated grief and depression were fitted. Based on the property of multi-level analysis to partition the total variation in variation from differences in measurements within participants (level 1) and between participants (level 2) and variation because of differences between families (level 3), we could establish the impact of the observed changes on the different levels. For all tests, we used a two tailed significance level of $P \leq 0.05$. A change corresponding with a Cohen's $d \geq 0.50$ is considered to be a clinically meaningful difference. ${ }^{25}$

\section{Sample size}

We used available information from 153 participants but did not base this number on an official sample size calculation. Instead, we elected to adopt accepted principle for an adequate sample size in such analyses, which calls for 10-15 participants or outcomes for each variable in the model. ${ }^{26}$ For our linear regression analyses, the multivariate models initially fitted 10 (model: complicated grief) and 16 (model: depression) variables. Based on this assumption our linear models were sufficiently powered to conduct these analyses. In general, longitudinal measurements usually increase the power of a study, while loss to follow-up adversely affects power. Both phenomena were present in our study.

\section{Results}

We included 74/401 suicide cases during recruitment (18\%) $\Downarrow$. At the time of death, the mean age of those who died $(n=74)$ was 44 (SD 17.0); 56/74 (76\%) were men. At T2 the mean number of years since the index suicide was 8.7 (SD 0.7). Between T1 and T2 one participant had committed suicide. Tables 1 and $2 \Downarrow \Downarrow$ shows the characteristics of the participants, the bereavement outcome, the history of mental health, and help seeking at T0, T1 and T2. Relatives of young (aged $<35$ ) people who committed suicide were well represented (34\% v $23 \%$ nationally; $\mathrm{P}=0.05)$ as were men in that group $(84 \% \vee 72 \%$ nationally; $\mathrm{P}=0.05) .{ }^{27}$ Based on several reasons for exclusion (given either by the general practitioners or by families who were approached but refused participation) we inferred that there was no clear selection bias in the sample. Also, during the study, we did not observe over-representation or under-representation of specific types of families. ${ }^{28}$ Given the relatively strong adherence of participants to the study, however, together with the fact that respondents indicated that participation was helpful (also stated by participants allocated to the control condition), we cannot rule out that a need for help and support might have introduced sample bias.

Table 2 shows that 10/153 (7\%) participants had a history of attempted suicide (compared with $2.7 \%$ of the Dutch 
population) $\Downarrow$. At baseline, 39/153 (26\%) participants suffered from suicide ideation, decreasing to $6 / 68(9 \%)$ at T2 which, during the bereavement course, is more than that in the general Dutch population (3.0\%). ${ }^{29}$ Table 2 also shows that throughout the bereavement course, $17-78 \%$ of the sample had received help from at least one resource.

Table $3 \Downarrow$ shows the bivariate associations with outcomes. Female sex predicted higher levels of depression, but not of complicated grief or suicide ideation. Children and in-laws were less likely than spouses to show symptoms of complicated grief and depression, whereas being a sibling was associated with lower depression than spouses. Personality features showed significant associations with all outcomes. Higher neuroticism and lower mastery were both associated with an increased risk and more self esteem was associated with a lower risk of outcomes. A history of clinical anxiety, clinical depression, and attempted suicide were all associated with an increased risk of depression, but not with complicated grief. Unlike previously attempted suicide, a history of clinical anxiety or depression was not associated with long term suicide ideation. Long term suicide ideation was strongly associated with an increased risk of complicated grief and depression. Help seeking was not associated with a lower risk of all outcomes, except for mutual support, which was associated with a lower risk of depression. The risk of complicated grief and depression decreased over time.

We subsequently developed final prediction models for complicated grief and depression (table 3 ) $\downarrow$. The following variables that showed a significant bivariate relation with outcome did not make the final prediction model: being a child of the deceased, being an in-law/other, self esteem, ever been clinically anxious, ever been clinically depressed, ever attempted suicide, mental healthcare, primary health, and family based cognitive behavioural therapy. Similarly, some variables made the final prediction model for certain outcome(s) but not for others. Long term complicated grief and depression are predicted by an overlapping set of variables; female sex and lower mastery, however, only independently predicted depression but not complicated grief. Suicide ideation is strongly associated with long term complicated grief and depression; all three outcomes are mutually strongly associated. Of all kinship relationships, parents are most likely to be at risk of complicated grief, whereas parents and siblings are less likely to be at risk of long term depression compared with spouses. Neither family based cognitive behavioural therapy nor help from the general practitioner or mental healthcare had an effect on the risk of complicated grief or depression, whereas mutual support is associated with an increased risk of complicated grief

Table $4 \Downarrow$ also shows that the risk of complicated grief and depression decreases over time. Between T0 and T1 we found a change corresponding with a Cohen's d effect size of 0.28 for depression and 0.36 for complicated grief; between $\mathrm{T} 0$ and $\mathrm{T} 2$ these figures are 0.94 for depression and 0.89 for complicated grief. The complicated grief scores can be explained by changes occurring at two levels - that is, between observations within individuals $(\beta=109.121$ (SE 11.008); $\mathrm{P}<0.001)$ and between individuals $(\mathrm{B}=53.2(\mathrm{SE}=16.3) ; \mathrm{P}=0.001)$, whereas depression can primarily be explained by changes between observations within individuals $(\mathrm{B}=45.9$ ( $\mathrm{SE}=4.2) ; \mathrm{P}<0.001)$.

\section{Discussion}

Complicated grief, depression, and suicide ideation are strongly associated in the long term course of bereavement after the suicide of a first degree relative or spouse. A history of clinical depression and/or anxiety and/or previous suicide attempts do not predict long term psychological and psychiatric difficulties after a loss through suicide. Depression is more likely to be predicted by individual factors generally associated with an increased risk of depression than by complicated grief. No help resources were significantly associated with long term symptoms of complicated grief, depression, or suicide ideation, except for mutual support, which was associated with an increased risk of complicated grief. In general, relatives bereaved after suicide recover from their bereavement in the course of time, whereas the magnitude of the change at 13 months is small for both depression and complicated grief.

\section{Limitations}

This study has several limitations. Firstly, because it was performed to investigate the effects of family based cognitive behavioural therapy on the one year course of bereavement, participants who felt a need for help immediately after the loss might be over-represented. This could have introduced selection bias as bereaved people who seek help generally have poorer psychological wellbeing. ${ }^{4}$ Help seeking was self reported (yes or no), and, because the number of sessions and the type of therapy administered by help resources (psychiatrist, psychologist, mental health nurse, social worker) remained unknown, this could have introduced some bias. Also the specific contents of mutual support (quantity, timing, group or individual, type of group, active or passive, and type of leadership) have not been assessed. In addition, it should be taken into account that data on mutual support in the first year of bereavement were collected in a period of time before online (mutual) support became generally available. Therefore, it is uncertain whether web based mutual support (the availability of which has accelerated in recent years) also predicts an increased risk of complicated grief. The findings, however, probably concern relatives involved in help seeking, thereby supporting the external validity of these findings. It is unclear whether the dichotomisation of suicide ideation affected the outcome. However, we elected to dichotomise Paykel suicide items, because the distribution of the data of this variable was highly skewed. To facilitate interpretation of this variable, we preferred dichotomisation of this variable rather than transforming it. Consequently, the cut-off point was set at scores $>8$, indicating considerable suicide ideation. ${ }^{12}$ It is unknown whether or how the families who dropped out might have introduced response bias.

\section{Comparison with other studies}

Outcomes from our study confirm previous findings of an increased risk of suicidal behaviour in relatives of individuals who kill themselves. ${ }^{3}$ Outcomes confirm that depression is more likely to be predicted by individual factors generally associated with an increased risk of depression, such as female $\operatorname{sex}^{30}$ and lower self efficacy, ${ }^{31}$ than by complicated grief. In addition, spouses show higher levels of depression than parents and siblings. This could be explained by difficulties that might arise when a spouse dies, such as financial and/or housing problems and becoming a single parent. Also, participants who lost a spouse might suffer from the loss of support and intimacy of the one they usually share their grief with. Family factors might also have played a role in the onset or maintenance of depression because suicide is known to be strongly associated with mental disorder. ${ }^{32}$ Therefore, participants might genetically share a vulnerability for the development of depression with the dead person. Clinical observations between $\mathrm{T} 0$ and $\mathrm{T} 1$ showed that families in which suicide occurred are sometimes burdened by 
psychiatric and psychosocial difficulties as well as high conflict, poor cohesion, and poor expressiveness even before the index suicide. These family features are associated with a more adverse bereavement outcome. ${ }^{28}$ This hypothesis is compatible with the observed changes in depression scores in our population that are explained by changes within participants, whereas changes in complicated grief are explained by changes within and between participants. Complicated grief seems to be more likely to be predicted by the trauma of losing a child, as also reported by others..$^{33}$ Clinical observations showed that parents and siblings receive more social support than spouses, possibly moderating the risk of depression in parents and siblings.

We earlier suggested that a history of psychiatric (co)morbidity before the index suicide increases the risk of psychiatric (co)morbidity after the suicide. ${ }^{14}$ We also found that family based cognitive behavioural therapy reduced maladaptive grief reactions, ${ }^{12}$ particularly in relatives who had suicide ideation. ${ }^{14}$ Given the lack of effect of this therapy on long term complicated grief, this effect seems to be transient. On the other hand, family based cognitive behavioural therapy might provide considerable relief in the initial period of intense grief without causing harm. Mutual support, sought by $4 / 153(6 \%)$ at T0 to $26 / 68$ (38\%) at T2 throughout the course of bereavement, was associated with an increased risk of complicated grief. In the catchment area, mutual support consisted mainly of small voluntary peer led or clergy led groups and/or individual contacts with peer leaders. We cannot rule out that general practitioners were more likely to include relatives who are at increased risk of complicated grief, and this could explain the positive association between mutual support and complicated grief, whereas relatives who benefited from mutual support might have eluded our view. Compared with relatives with lower symptom levels, those with high symptom levels of complicated grief might be more likely to seek contact with other bereaved relatives to share their grief. Alternatively, individuals who seek mutual support might be inclined to ruminative coping, placing them at risk of avoidance rather than of recovery ${ }^{34}$ and thereby increasing the risk of complicated grief. ${ }^{35}$ Recovery from bereavement is ultimately considered to be a process of restoration and coming to sense with the reality of the loss. Suicide ideation is characterised by feelings of hopelessness and perceptions that life is not worth living. These feelings and thoughts can inhibit adjustment, which is considered necessary to recover from bereavement. Suicide ideation can interfere with effective emotional processing and therefore increase the risk of complicated grief. It should be emphasised, however, that the outcomes of the prediction models do not allow us to draw conclusions about causal associations between the use of help resources and long term complicated grief and depression. As help seeking is measured on a yes/no scale, it lacks nuance. In particular, the positive association observed between mutual support and an increased risk of complicated grief might suggest that mutual support is iatrogenic; however, this assumption might not be valid. Therefore, the observed positive association between help seeking and complicated grief should be interpreted with caution.

No evidence is available for any interventions in prevention of complicated grief. ${ }^{36}$ Negative beliefs about the self and the future are said to be responsible for the onset and maintenance of complicated grief ${ }^{35}$ and suicide ideation. ${ }^{37}$ One study found that cognitions like "the future holds no meaning or purpose" and "life cannot be fulfilling without the lost" discriminated best between low and high complicated grief, ${ }^{38}$ suggesting that similar negative cognitions play a role in the onset of both complicated grief and suicide ideation. This idea might be examined in future research. It would also be useful to determine whether the onset of complicated grief can be prevented by cognitive behavioural treatment of suicide ideation ${ }^{39}$ and to study whether suicide ideation is a consequence or a cause of complicated grief. This could be explored in a prospective study among relatives of people who attempt suicide. Possible outcomes could then be generalised to relatives bereaved by causes other than suicide, such as from natural causes, unintentional injury, or homicide.

The association between previous suicide attempts and long term suicide ideation provides support for the stress-diathesis model for suicidal behaviour, ${ }^{40}$ proposing that suicidal behaviour is not only determined by a stressor (such as mental disorder, experience of loss), but also by a constitutional predisposition to this type of behaviour. Unfortunately, because low power does not allow us to adjust suicide ideation at 8-10 year follow-up for other variables, the findings should be interpreted with caution.

\section{Conclusions and policy implications}

Our findings support the necessity of assessing the history of suicide attempts in individuals bereaved by suicide to determine the risk of complicated grief and depression in the long term. Over the years, mutual support is associated with an increased risk of complicated grief, suggesting that shortly after a suicide, healthcare providers should be cautious about indiscriminately recommending mutual support to bereaved relatives in case of emerging symptoms of depression, complicated grief, and suicide ideation.

We thank Janyte Holwerda and Alberta ten Klooster for their assistance with data collection, and M Y Berger and J Neeleman for their overall support.

Contributors: MdG designed the study, obtained funding, collected data, was responsible for data management and interpretation, wrote the draft, assisted in data analyses, and is guarantor. BJK designed and performed the data analyses, wrote the analyses section, and approved the final draft.

Funding: This study was funded by ZONMW (Netherlands Organisation for Health Research and Development) No 60-60100-98-052.

Competing interest: All authors have completed the ICMJE uniform disclosure form at www.icmje.org/coi_disclosure.pdf (available on request from the corresponding author) and declare: no support from any organisation for the submitted work; no financial relationships with any organisations that might have an interest in the submitted work in the previous three years; no other relationships or activities that could appear to have influenced the submitted work.

Ethical approval: The study was approved by the medical ethical committee of the University Medical Center Groningen (METc 2009/052). All participants provided informed consent.

Data sharing: The dataset and additional data are available from the corresponding author. Consent for data sharing was not obtained but the presented data are anonymous and risk of identification is low.

World Health Organization (WHO). Mortality database. WHO, 2003.

2 Cerel J, Padgett J, Cornweel Y, Reed G. A call for research: the need to better understand the impact of support groups for suicide survivor. Suicide Life Threat Behav 2009;39:269-81.

3 Qin P, Agerbo E, Mortensen PB. Suicide risk in relation to family history of completed suicide and psychiatric disorders: a nested case-control study based on longitudinal registers. Lancet 2002;360:1126-30.

4 Stroebe M, Schut H, Stroebe W. Health outcomes of bereavement. Lancet 2007;370:1960-73.

5 Agerbo E. Midlife suicide risk, partner's psychiatric illness, spouse and child bereavement by suicide or other modes of death: a gender specific study. J Epidemiol Community Health 2005;59:407-12.

6 Lichtenthal WG, Cruess DG, Prigerson HG. A case for establishing complicated grief as a distinct mental disorder in DSM-V. Clin Psychology Rev 2004;24:637-62. 


\section{What is already known on this topic}

Grief counselling can be effective in decreasing the risk of problematic grief in individuals at increased risk of adverse outcome after bereavement

Despite the high risk status of relatives bereaved by suicide, there is no clear evidence for the effectiveness of such programmes

Shortly after a suicide $20 \%$ of relatives suffer from suicide ideation

Little is known about the consequences of suicide ideation on the course of bereavement after suicide

\section{What this study adds}

This long term study of the course of bereavement of a community based sample of first degree relatives and spouses bereaved after suicide showed that symptoms of complicated grief, depression, and suicide ideation are strongly associated

A history of attempted suicide before the index suicide predicts suicide ideation during bereavement

Though relatives recover from the bereavement in the course of time, the decrease of symptoms in the first year is likely to be small

Received mutual support is associated with an increased risk of complicated grief, but no conclusions can be drawn about any causal association

7 Prigerson HG, Horowitz MJ, Jacobs SC, Parkes C, Goodkin A, Raphael B, et al. Prolonged grief disorder: psychometric validation of criteria proposed for $D S M-V$ and $I C D-11$ PlosMed 2009;6:e1000121.

8 Prigerson HG, Bridge J, Maciejewski PK, Beery LC, Rosenheck RA, Jacobs SC, et al. Influence of traumatic grief on suicidal ideation among young adults. Am J Psychiatry 1999;156:1994-5.

9 Szanto K, Shear MK, Houck PR, Reynolds CF, Frank E, Caroff K, et al. Indirect self-destructive behavior and overt suicidality in patients with complicated grief. $J$ Clin Psychiatry 2006;67:233-9.

10 McDaid C, Trowman R, Golder S, Hawton K, Sowden A. Interventions for people bereaved through suicide: systematic review. Br J Psychiatry 2008;193:438-43.

11 De Groot MH, van der Meer K, Burger H. A survey of Dutch general practitioners' attitudes towards help seeking of suicide bereaved relatives. Fam Pract 2009;26:372-5.

12 De Groot MH, de Keijser J, Neeleman J, Kerkhof AJFM, Nolen WA, Burger H. Cognitive behaviour therapy to prevent complicated grief among relatives and spouses bereaved by suicide: cluster randomised controlled trial. BMJ 2007;334:994-6.

13 McMenamy J, Jordan J, Mitchell A. What do suicide survivors tell us they need? Results of a pilot study. Suicide Life Threat Behav 2008;38:375-89.

14 De Groot MH, Neeleman J, van der Meer K, and Burger $\mathrm{H}$. The effectiveness of family-based cognitive-behavior grief therapy to prevent complicated grief in relatives of suicide victims. The mediating role of suicide ideation. Suicide Life Threat Behav 2010;40:425-37.

15 De Groot MH, de Keijser J, Neeleman J. Grief shortly after suicide and natural death. A comparative study among spouses and first-degree relatives. Suicide Life Threat Behav 2006;36:419-33.

16 Neeleman J, Bijl R, Ormel J. Neuroticism, a central link between somatic and psychiatric morbidity: path analysis of prospective data. Psychological Med 2004;34:521-31.

17 Eysenck SBG, Eysenck HJ. An improved short questionnaire for the measurement of extraversion and neuroticism. Life Science 1964;305:1103-9.

18 Pearlin LI,.Schooler C. The structure of coping. J Health Soc Behav 1978;19:2-21.

19 Rosenberg M. The measurement of self-esteem. Society and the adolescent self-image. Princeton University Press, 1965:16-36.

20 Stroebe W, Schut HAW. Risk factors in bereavement outcome: a methodological and emperical review. In: Stroebe MS, Hansson RO, Stroebe W, Schut H, eds. Handbook of bereavement research. Consequences, coping and care. American Psychological Association Press, 2001:349-71.

21 Boelen PA, van den Bout J, de Keijser J, Hoijtink $\mathrm{H}$. Reliability and validity of the Dutch version of the inventory of traumatic grief (ITG). Death Stud 2003;27:227-47.

22 Radloff LS. The CES-D scale: a self-report depression scale for research in the general population. Appl Psychol Measure 1977;1:385-401.

23 Paykel E, Myers JK, Lindenthal JJ, Tanner J. Suicidal feelings in the general population: a prevalence study. Br J Psychiatry 1974;124:460-9.

24 World Health Organization. Schedules for clinical assessment in neuropsychiatry (SCAN). WHO, 1992.

25 Middel B, van Sonderen E. Statistical significant change versus relevant or important change in (quasi) experimental design: some conceptual and methodological problems in estimating magnitude of intervention-related change in health services research. Int J Integr Care 2002;2:e15.
26 Peduzzi P, Concato J, Kemper E, Holford T, Feinstein A. A simulation study of the number of events per variable in logistic regression analysis. J Clin Epidemiol 1996;49:1373-9.

27 Netherlands Statistics (Centraal Bureau voor de Statistiek). 2006. http://statline cbs.n. statweb/

28 Kissane DW, Bloch S, Dowe DL, Snyder RD, Onghena P, McKenzie DP, et al. The Melbourne family grief study I: Perceptions of family functioning in bereavement. $A m \mathrm{~J}$ Psychiatry 1996;153:650-8.

29 Bernal M, Haro JM, Bernert S, Brugha T, De Graaf R, Bruffearts R, et al. Risk factors for suicidality in Europe: results from the ESEMED study. J Affect Dis 2007;101:27-34.

30 Seedat S, Scott K, Angermeyer MC, Berglund P, Bromet E, Brugha TS, et al. Cross-national associations between gender and mental disorders in the World Health Organization World Mental Health Surveys. Arch Gen Psychiatry 2009;66:785-95.

31 Gopinath S, Katon W, Russo J, Ludman E, Gop. Clinical factors associated with relapse in primary care patients with chronic or recurrent depression. J Affect Dis 2007;57-63.

32 Hawton K, van Heeringen K. Suicide. Lancet 2009;393:1372-81.

33 Wijngaards-de Meij L, Stroebe M.S., Schut H, Stroebe W, van den Bout J, van der Heijden $\mathrm{P}$, et al. Couples at risk following the death of their child: predictors of grief versus depression. J Consult Clin Psychol 2007;73:617-23.

34 Nolen-Hoeksema S. Ruminative coping and adjustment to bereavement. In: Stroebe MS, Hansson RO, Stroebe W, Schut HAW, eds. Handbook of Bereavement Research. Consequences, Coping, and Care. American Psychological Association, 2001:545-63.

35 Boelen PA, van den Hout MA, van den Bout J. A cognitive-behavioral conceptualization of complicated grief. Clin Psychol Sci Pract 2006;13:109-28.

36 Wittouck C, Van Autreve S, de Jaegere E, Portzky G, van Heeringen K. The prevention and treatment of complicated grief: a meta analysis. Clin Psychology Rev 2010;31:69-78.

37 Ellis T, Rutherford B. Cognition and suicide: two decades of progress. Int $J$ Cognitive Therapy 2008;1:47-68.

38 Boelen PA, van den Bout $\mathrm{J}$, van den Hout MA. Negative cognitions and avoidance in emotional problems after bereavement: A prospective study. Behav Res Ther 2006:44:1657-72.

39 Brown GK, Ten Have T, Henriques GR, Xie SX, Hollander JE, Beck AT. Cognitive therapy for the prevention of suicide attempts. A randomised controlled trial. JAMA 2005;294:563-70.

40 Mann JJ, Waternaux C, Haas GL, Malone KM.. Toward a clinical model of suicidal behavio in psychiatric patients. Am J Psychiatry 1999;156:181-9.

Accepted: 20 August 2013

\section{Cite this as: BMJ 2013;347:f5519}

This is an Open Access article distributed in accordance with the Creative Commons Attribution Non Commercial (CC BY-NC 3.0) license, which permits others to distribute, remix, adapt, build upon this work non-commercially, and license their derivative works on different terms, provided the original work is properly cited and the use is non-commercial. See: http://creativecommons.org/licenses/by-nc/3.0/. 


\section{Tables}

Table 1 | Sociodemographic features and personality features of 153 relatives in 74 families bereaved by suicide No (\%) of participants*

\begin{tabular}{|c|c|}
\hline Mean (SD) age of dead person (years) & $44(17.0)$ \\
\hline Dead person was male & $56(76)$ \\
\hline Male respondent & $50(33)$ \\
\hline Mean (SD) age of respondent (years) & $42(14.1)$ \\
\hline \multicolumn{2}{|l|}{ Marital status before suicide: } \\
\hline Single & $17(11)$ \\
\hline Divorced & $10(7)$ \\
\hline Married/cohabiting & $81(52)$ \\
\hline Widowed & $39(26)$ \\
\hline Other & $6(4)$ \\
\hline \multicolumn{2}{|l|}{ Relationship to dead person: } \\
\hline Spouse & $37(24)$ \\
\hline Parent & $36(23)$ \\
\hline Child & $37(24)$ \\
\hline Sibling & $30(20)$ \\
\hline In-law/other & $13(9)$ \\
\hline Mean (SD; range) size of household (including respondent) & $2.4(1.3 ; 1-5)$ \\
\hline Household shared with dead person & $56(37)$ \\
\hline Mean (SD) size of family clusters (excluding deceased) & $2.1(1.1)$ \\
\hline \multicolumn{2}{|l|}{ No of participants per cluster: } \\
\hline 1 & $31(42)$ \\
\hline 2 & $17(23)$ \\
\hline 3 & $16(21)$ \\
\hline 4 & $8(11)$ \\
\hline 5 & $2(3)$ \\
\hline \multicolumn{2}{|l|}{ Mean (SD) scores on personality features (score range) $\ddagger$} \\
\hline Neuroticism (0-12) & $5.7(3.6)$ \\
\hline Mastery $(7-35) \dagger$ & $15.6(5.3)$ \\
\hline Self esteem (10-40) & $32.7(5.5)$ \\
\hline
\end{tabular}

*Unless stated otherwise.

†Lower score indicates stronger sense of control.

$\ddagger$ Assessed at 2.5 months after loss. 
Table 2| Mental health features of $\mathbf{1 5 3}$ relatives in $\mathbf{7 4}$ families bereaved by suicide*

\begin{tabular}{|c|c|}
\hline & No $(\%)$ of participants† \\
\hline \multicolumn{2}{|l|}{ Mental health } \\
\hline \multicolumn{2}{|l|}{ Mean (SD) complicated grief (range 0-129): } \\
\hline At 2.5 months $(n=153)$ & $75.9(20.3)$ \\
\hline At 13 months $(n=139)$ & $67.9(22.8)$ \\
\hline At $96-120$ months $(n=68)$ & $57.4(21.6)$ \\
\hline \multicolumn{2}{|l|}{ Mean (SD) depression (range 0-60): } \\
\hline At 2.5 months $(n=153)$ & $20.6(12.3)$ \\
\hline At 13 months $(n=139)$ & $14.0(12.0)$ \\
\hline At $96-120$ months $(n=68)$ & $10.5(8.6)$ \\
\hline \multicolumn{2}{|l|}{ Suicide ideation $(1=y e s, 0=n o):$} \\
\hline At 2.5 months $(n=153)$ & $39(26)$ \\
\hline At 13 months $(n=139)$ & $23(15)$ \\
\hline At $96-120$ months $(n=65)$ & $6(9)$ \\
\hline \multicolumn{2}{|l|}{ History of mental health } \\
\hline Any clinical depression before suicide $(1=y e s, 0=n o)(n=136) \ddagger$ & $34(22)$ \\
\hline Any clinical anxiety before suicide $(1=y e s, 0=n o)(n=136) \ddagger$ & $38(25)$ \\
\hline Any attempted suicide before index suicide ( $1=y e s, 0=n o)(n=153)$ & $10(7)$ \\
\hline \multicolumn{2}{|l|}{ Help seeking } \\
\hline \multicolumn{2}{|l|}{ Had mutual support ( $1=y e s, 0=n o):$} \\
\hline From suicide until 2.5 months $(n=153)$ & $1(1)$ \\
\hline From 2.5 to 13 months $(n=138)$ & $24(17)$ \\
\hline From 13 to $96-120$ months $(n=59)$ & $26(44)$ \\
\hline \multicolumn{2}{|l|}{ Received mental healthcare $(1=y e s, 0=n o)$ : } \\
\hline From suicide until 2.5 months $(n=153)$ & $39(26)$ \\
\hline From 2.5 to 13 months $(n=138)$ & $51(37)$ \\
\hline From 13 to $96-120$ months $(n=55)$ & $23(37)$ \\
\hline \multicolumn{2}{|l|}{ Received primary healthcare $(1=y e s, 0=$ no): } \\
\hline From the suicide until 2.5 months $(n=153)$ & $58(40)$ \\
\hline From 2.5 to 13 months $(n=138)$ & $85(62)$ \\
\hline From 13 to $96-120$ months $(n=63)$ & $49(78)$ \\
\hline \multicolumn{2}{|l|}{ Received FBT ( $1=y e s, 0=$ no): } \\
\hline From 3 to 6 months $(n=153)$ & $92(60)$ \\
\hline
\end{tabular}

FBT=randomly allocated family based cognitive behavioural therapy.

*Assessed at 2.5 months after loss, unless stated otherwise.

†Unless stated otherwise.

$\ddagger$ Assessed at T1 (13 months after suicide). 
Table 3| Bivariate associations between factors and complicated grief, depression, and suicide ideation for 8-10 year course of bereavement after suicide in community based sample of first degree relatives and spouses $(n=153)$. Figures are $B$ regression coefficients or odds ratios ( $95 \%$ confidence interval)

\begin{tabular}{|c|c|c|c|}
\hline \multirow[b]{2}{*}{ Long term } & \multicolumn{2}{|c|}{ B (95\% Cl), P value } & \multirow[b]{2}{*}{ OR $(95 \% \mathrm{Cl}), \mathrm{P}$ value for suicide ideation } \\
\hline & Complicated grief & Depression & \\
\hline \multicolumn{4}{|l|}{ Sociodemographic features: } \\
\hline Female respondent & 0.1 (5.2 to 5.4$), 0.971$ & 3.9 (0.9 to 6.9$), 0.012$ & $-1.4(-2.5$ to -0.7$), 0.336$ \\
\hline \multicolumn{4}{|l|}{ Baseline personality features: } \\
\hline Neuroticism (range 0-12) & 2.6 (1.9 to 3.2$),<0.001$ & 2.0 (1.7 to 2.3$),<0.001$ & $1.3(1.2$ to 1.5$),<0.001$ \\
\hline Mastery (range $0-35)^{*}$ & $1.4(0.9$ to 1.9$),<0.001$ & $1.1(0.8$ to 1.3$),<0.001$ & $1.2(1.1$ to 1.3$),<0.001$ \\
\hline Self esteem (range 0-40) & $-1.2(-1.7$ to -0.7$),<0.001$ & $-0.1(-1.2$ to -0.6$),<0.001$ & $0.9(0.8$ to 0.9$),<0.001$ \\
\hline \multicolumn{4}{|c|}{ Relationship to dead person ( $1=y e s, 0=$ no): } \\
\hline Spouse (reference) & 1.0 & 1.0 & - \\
\hline Parent & $6.8(-1.3$ to 14.9$), 0.102$ & $0.4(-4.2$ to 4.5$), 0.952$ & NA \\
\hline Child & $-9.4(-16.4$ to -2.3$), 0.009$ & $-6.6(-10.5$ to -2.4$), 0.002$ & NA \\
\hline Sibling & $-4.5(-13.0$ to 3.9$), 0.293$ & $-5.6(-10.2$ to -0.9$), 0.019$ & NA \\
\hline In-law/other relative & $-10.9(-20.2$ to -1.6$), 0.022$ & $-5.6(-11.1$ to 0.1$), 0.047$ & NA \\
\hline \multicolumn{4}{|c|}{ History of mental health $(1=y e s, 0=$ no): } \\
\hline Any clinical anxiety & 3.3 (2.6 to 9.1$), 0.269$ & 5.1 (1.9 to 8.4$), 0.002$ & 1.5 (0.8 to 3.0$), 0.227$ \\
\hline Any clinical depression & 4.1 (2.0 to 10.2$), 0.190$ & $5.7(2.4$ to 9.1$),<0.001$ & 1.5 (0.8 to 3.1$), 0.226$ \\
\hline Any attempted suicide & $10.9(-0.01$ to 21.9$), 0.052$ & $7.9(1.7$ to 14.1$), 0.013$ & 5.5 (1.8 to 16.7$), 0.003$ \\
\hline \multicolumn{4}{|l|}{ Mental health: } \\
\hline Complicated grief (range 0-129) & NA & $0.41(0.36$ to 0.44$),<0.001$ & $1.1(1.0$ to 1.1$),<0.001$ \\
\hline Depression (range 0-60) & $1.2(1.1$ to 1.3$),<0.001$ & NA & $1.1(1.07$ to 1.13$),<0.001$ \\
\hline Suicide ideation ( $1=y e s, 0=$ no) & $21.1(15.7$ to 26.4$),<0.001$ & $13.6(10.5$ to 16.7$),<0.001$ & NA \\
\hline \multicolumn{4}{|c|}{ Help seeking over time $(1=y e s, 0=$ no): } \\
\hline Had mutual support & $-5.3(-10.5$ to 0.0$), 0.05$ & $-5.7(-8.9$ to -2.5$), 0.001$ & 0.7 (0.3 to 1.7$), 0.437$ \\
\hline Received mental healthcare & $-1.5(-5.8$ to 2.8$), 0.502$ & $-2.6(-5.2$ to -0.9$), 0.058$ & 0.7 (0.4 to 1.3$), 0.253$ \\
\hline Received primary healthcare & $-1.1(-4.9$ to 2.6$) 0.553$ & $-1.1(-3.5$ to 1.2$), 0.347$ & 0.9 (0.5 to 1.6$), 0.782$ \\
\hline Received FBT & $2.3(-5.7$ to 10.3$) 0.574$ & $3.4(-0.5$ to 7.3$), 0.088$ & 1.4 (0.6 to 3.3 ), 0.424 \\
\hline \multicolumn{4}{|l|}{ Time (months) since suicide: } \\
\hline 2.5 (T0) (reference) & 1.0 & 1.0 & - \\
\hline $13(\mathrm{~T} 1)$ & $-8.4(-11.2$ to 5.6$),<0.001$ & $-7.0(-8.9$ to -5.2$),<0.001$ & NA \\
\hline $96-100(T 2)$ & $-19.8(-23.5$ to -16.1$),<0.001$ & $-10.8(-13.2$ to -8.4$),<0.001$ & NA \\
\hline
\end{tabular}


Table 4| Final prediction models of 8-10 year course of complicated grief and depression in community based sample of first degree relatives and spouses $(n=153)$ bereaved by suicide

\begin{tabular}{|c|c|c|}
\hline & \multicolumn{2}{|c|}{$\mathrm{B}(95 \% \mathrm{Cl}), \mathrm{P}$ value } \\
\hline & Complicated grief & Depression \\
\hline \multicolumn{3}{|l|}{ Sociodemographic features: } \\
\hline Female respondent & - & 2.8 (4.6 to 1.1$), 0.001$ \\
\hline \multicolumn{3}{|l|}{ Baseline personality features: } \\
\hline Neuroticism (range 0-12) & 0.7 (0.1 to 1.3$), 0.032$ & $0.7(0.4$ to 1.0$),<0.001$ \\
\hline Mastery* (range 7-35) & - & $4.0(1.5$ to 6.4$), 0.002$ \\
\hline \multicolumn{3}{|c|}{ Relationship to dead person ( $1=y e s, 0=n o)$ : } \\
\hline Spouse (reference) & 1.0 & 1.0 \\
\hline Parent & $5.5(0.1$ to 10.9$), 0.046$ & $-2.7(-5.1$ to -0.4$), 0.024$ \\
\hline Sibling & - & $-2.6(-5.2$ to -0.1$), 0.040$ \\
\hline \multicolumn{3}{|l|}{ Mental health: } \\
\hline Complicated grief (range 0-129) & NA & 0.3 (0.2 to 0.3$),<0.001$ \\
\hline Depression (range 0-60) & $<0.001$ & NA \\
\hline Suicide ideation ( $1=\mathrm{yes}, 0=\mathrm{no}$ ) & 7.1 (2.8 to 11.3$),<0.001$ & $4.0(1.5$ to 6.4$),<0.001$ \\
\hline \multicolumn{3}{|l|}{ Help seeking ( $1=$ yes, $0=n o)$ : } \\
\hline Mutual support & 6.4 (1.8 to 11.0$), 0.006$ & - \\
\hline \multicolumn{3}{|l|}{ Time (months) since suicide: } \\
\hline 2.5 (T0) (reference) & 1.0 & 1.0 \\
\hline $13(\mathrm{~T} 1)$ & $-2.8(-5.5$ to -0.4$), 0.046$ & $-5.5(-7.3$ to -3.8$),<0.001$ \\
\hline $96-100(\mathrm{~T} 2)$ & $-11.9(-16.1$ to -7.7$), 0.046$ & $-5.6(-8.0$ to -3.3$),<0.001$ \\
\hline
\end{tabular}

$\mathrm{NA}=$ not applicable.

*Lower scores indicate higher sense of control. 


\section{Figure}

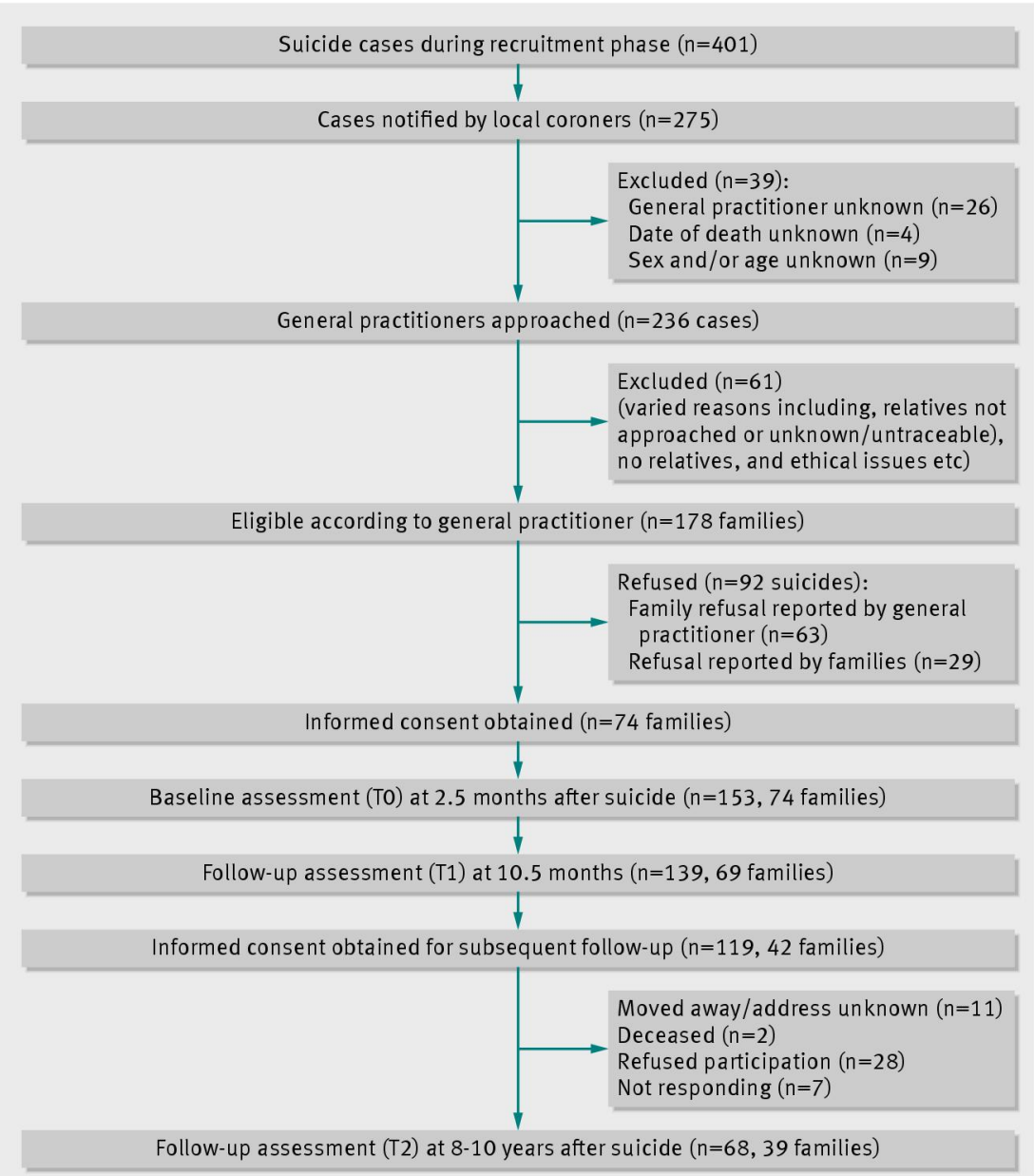

Flow of participants during study 